\title{
Current approaches to the diagnosis of herpes genitalis
}

\author{
E. M. BELSEY AND M. W. ADLER \\ From the Departments of Venereology and Genitourinary Medicine and Community Medicine, \\ Middlesex Hospital and Medical School, London
}

SUMMARY The current methods of diagnosing and treating herpes genitalis in clinics for sexually transmitted diseases in England and Wales are reported. Virus cultures were used as a diagnostic test in some or all patients in nearly two-thirds of clinics. Darkground examinations were performed on all or selected patients in most clinics, but fewer than half the clinics performed them on three or more separate occasions. In over $80 \%$ of clinics attempts were made to see some or all contacts of patients with herpes. The treatments prescribed varied, the commonest being saline washes, idoxuridine, and oral antibiotics. Serological tests were repeated after the disappearance of the lesions in $90 \%$ of clinics, while in $60 \%$ of clinics women with herpes genitalis were advised to have cytological examination at regular intervals in future. The importance of excluding syphilis in patients presenting with genital ulceration, the most appropriate treatments for herpes, and the possible association between the disease and cervical carcinoma are discussed.

\section{Introduction}

Although herpes genitalis remains one of the less common sexually transmitted diseases seen in clinics, it does present several special problems. Firstly, the disease often recurs; secondly, an effective treatment has yet to be found; thirdly, the question of its association with cervical cancer remains unresolved. The importance of herpes genitalis should therefore not be underestimated.

The methods used by clinics for sexually transmitted diseases in England and Wales were surveyed (Adler et al., 1978). The diagnostic techniques used for herpes genitalis and its treatment are now reported.

\section{Results}

DIAGNOSTIC FACILITIES AND THEIR USE

\section{Cultures}

In a previous paper (Adler et al., 1978) it was reported that, of the 175 clinics in England and Wales included in the survey, 171 treated men and 173 treated women. In $126(74 \%)$ of the clinics where men were treated and in $127(73 \%)$ where women were seen a virus culture service was available. However, it was not used in $18(14 \%)$ of the clinics for men nor in the same number of clinics for women, even

Address for reprints: E. M. Belsey, Medical Research Council, Sexually Transmitted Diseases Project, James Pringle House, 73-75 Charlotte Street, London W1P 1 LB

Received for publication 11 October 1977 though it was available. In men presenting with genital ulceration, virus cultures were used routinely to make or exclude the diagnosis of herpes genitalis in $55 \%$ of clinics, and in women this was so in $56 \%$ of clinics (Table 1). In a further $8 \%$ of clinics virus cultures were used for selected male patients, while in $7 \%$ they were used for selected females. In more than one-third of clinics, however, the diagnosis was made from the clinical history and examination, without pathological confirmation.

In clinics where virus cultures were not used in every case the most common reasons for selecting patients were that the attack of herpes was particularly severe, or that the doctor was unable to determine clinically whether the patient was suffering from herpes or from syphilis.

\section{Serum antibody complement-fixation tests and cytology}

Serum antibody complement-fixation tests were performed in $30 \%$ of all clinics. Routine cytology

Table 1 Methods used to diagnose herpes genitalis in addition to clinical history and examination

\begin{tabular}{|c|c|c|c|c|}
\hline \multirow[b]{2}{*}{ Method } & \multicolumn{2}{|c|}{ Men } & \multicolumn{2}{|c|}{ Women } \\
\hline & No. & $\%$ & No. & $\%$ \\
\hline \multicolumn{5}{|l|}{ Virus cultures } \\
\hline In all cases & 94 & $55 \cdot 0$ & 97 & $56 \cdot 1$ \\
\hline In selected cases & 14 & $8 \cdot 2$ & 12 & 6.9 \\
\hline No pathological confirmation & 63 & $36 \cdot 8$ & 64 & $37 \cdot 0$ \\
\hline & 171 & $100 \cdot 0$ & 173 & $100 \cdot 0$ \\
\hline
\end{tabular}


was carried out in over half $(54 \%)$ of the clinics treating women, but cervical virus cultures were performed in only 44 clinics, $35 \%$ of those with a virus culture service.

\section{Darkground microscopy}

Darkground examinations to exclude syphilis were performed on all men with genital ulceration in $58 \%$ of clinics, on selected patients in $36 \%$, and were not performed at all in 11 clinics $(6 \%)$ (Table 2). The corresponding figures for women were similar. Table 3 shows the reasons given for selecting

Table 2 Clinics performing darkground examinations on patients with genital ulceration

\begin{tabular}{lrrrrrr}
\hline & \multicolumn{2}{l}{ Men } & & \multicolumn{2}{l}{ Women } \\
\cline { 2 - 3 } \cline { 6 - 7 } Darkground examination & No. & $\%$ & & No. & \multicolumn{1}{c}{$\%$} \\
\hline All patients & 99 & 57.9 & & 96 & $55 \cdot 5$ \\
Selected patients & 61 & $35 \cdot 7$ & & 66 & $38 \cdot 1$ \\
Never & 11 & 6.4 & & 11 & $6 \cdot 4$ \\
& 171 & $100 \cdot 0$ & & 173 & $100 \cdot 0$ \\
\hline
\end{tabular}

Table 3 Reasons given for selecting cases for darkground examination

\begin{tabular}{|c|c|c|c|c|}
\hline \multirow[b]{2}{*}{ Reason } & \multirow{2}{*}{$\frac{M e n}{\text { No. }}$} & \multirow{2}{*}{$\frac{(N=61)}{\%}$} & \multicolumn{2}{|c|}{ Women $(N=66)$} \\
\hline & & & No. & $\%$ \\
\hline $\begin{array}{l}\text { Clinical appearance of syphilis/ } \\
\text { atypical of herpes } \\
\text { Patient's occupation } \\
\text { Homosexual patient } \\
\text { Other }\end{array}$ & $\begin{array}{r}57 \\
5 \\
4 \\
6\end{array}$ & $\begin{array}{r}93.4 \\
8 \cdot 2 \\
6.6 \\
9.8\end{array}$ & $\begin{array}{r}62 \\
5 \\
0 \\
6\end{array}$ & $\begin{array}{r}93.9 \\
7.6 \\
0.0 \\
9.1\end{array}$ \\
\hline
\end{tabular}

patients for darkground examinations if they were not performed routinely. The criterion for selection most often given, by consultants working in 57 clinics for men and 62 clinics for women, was that the case was atypical of herpes or had the clinical appearance of syphilis. Other reasons given were that the patient was homosexual or had an occupation likely to lead to a relatively high risk of contracting syphilis. In 51 clinics for men only one of the reasons listed was mentioned, while two reasons were given in nine, and three in one clinic; in 59 clinics for women one reason was mentioned and two reasons were given in seven clinics.

Although a large proportion of physicians reported that darkground examinations were performed to establish the initial diagnosis in some or all cases, in $30 \%$ of the clinics they were carried out once only (Table 4). In a further $30 \%$ of clinics they were performed on two occasions, while in the remaining clinics they were performed three or more times. The number of occasions on which darkground examinations were carried out did not differ between clinics in which they were performed in all cases and those in which they were performed in selected cases.

FREQUENCY OF DIAGNOSTIC TESTS

Clinics in which virus cultures were used routinely as a method of diagnosis were compared with those which used them in selected cases and those which did not use them at all, to find out if these figures differed from those on darkground examinations to exclude syphilis. It was found that darkground examinations were equally likely to be performed in clinics using virus cultures in some or all cases as in those clinics in which virus cultures were not used. The number of darkground examinations performed was also found not to differ between clinics using cultures in all cases, in selected cases, or not at all.

\section{EXAMINATION OF CONTACTS}

In approximately one-half of clinics attempts were made to see all contacts of patients suffering from herpes genitalis (Table 5). Consultants working in another $32 \%$ of clinics tried to see contacts in selected cases, while in the remaining clinics no attempts were made. Table 6 shows the criteria for

Table 4 Number of occasions on which darkground examinations performed

\begin{tabular}{lrrrrr}
\hline & \multicolumn{3}{c}{ Men } & & \multicolumn{2}{l}{ Women } \\
\cline { 2 - 3 } \cline { 5 - 6 } No. of occasions & No. & $\%$ & & No. & \multicolumn{1}{c}{$\%$} \\
\hline One & 48 & $30 \cdot 0$ & & 49 & $30 \cdot 2$ \\
Two & 49 & $30 \cdot 6$ & & 49 & $30 \cdot 2$ \\
Three & 58 & $36 \cdot 3$ & & 59 & $36 \cdot 4$ \\
More than three & 5 & $3 \cdot 1$ & & 5 & $3 \cdot 1$ \\
& 160 & $100 \cdot 0$ & & 162 & $100 \cdot 0$ \\
\hline
\end{tabular}

Table 5 Clinics attempting to see contacts of patients with herpes genitalis

\begin{tabular}{lccccc}
\hline & \multicolumn{2}{c}{ Male contacts } & & \multicolumn{2}{c}{ Female contacts } \\
Contacts & No. & $\%$ & & No. & $\%$ \\
\hline All & 84 & $49 \cdot 1$ & & 85 & $50 \cdot 3$ \\
Selected & 54 & $31 \cdot 6$ & & 55 & $32 \cdot 5$ \\
None & 33 & $19 \cdot 3$ & & 29 & $17 \cdot 2$ \\
& $171^{*}$ & $100 \cdot 0$ & & 169 & $100 \cdot 0$ \\
\hline
\end{tabular}

*169 clinics seeing both sexes, plus two clinics seeing only men

Table 6 Reasons given for seeing selected contacts

\begin{tabular}{|c|c|c|c|c|}
\hline \multirow[b]{2}{*}{ Reason } & \multicolumn{2}{|c|}{$\begin{array}{l}\text { Male contacts } \\
(N=54)\end{array}$} & \multicolumn{2}{|c|}{$\begin{array}{l}\text { Female contacts } \\
(N=55)\end{array}$} \\
\hline & No. & $\%$ & No. & $\%$ \\
\hline Symptoms/positive history & 31 & $57 \cdot 4$ & 30 & $54 \cdot 5$ \\
\hline $\begin{array}{l}\text { Regular partner } \\
\text { Recurrent attacks in original }\end{array}$ & 13 & $24 \cdot 1$ & 16 & $29 \cdot 1$ \\
\hline $\begin{array}{l}\text { Recurrent attacks in original } \\
\text { patient }\end{array}$ & 11 & 20.4 & 11 & $20 \cdot 0$ \\
\hline If severe in female & 2 & $3 \cdot 7$ & 0 & $0 \cdot 0$ \\
\hline Not known & 0 & 0.0 & 3 & $5 \cdot 5$ \\
\hline
\end{tabular}


seeing contacts given by the clinics in which only selected contacts were seen. The most common reason was that the patient reported that his or her sexual contact had signs or symptoms of genital ulceration. Some consultants were even more selective and would see only the patient's regular partner or contacts of patients suffering from recurrent attacks of herpes. In 51 clinics only one criterion for seeing male contacts was given, while in three clinics two criteria were mentioned; of the clinics in which attempts to see selected female contacts were made, one criterion was given in 47 , two were given in five, and in three clinics the criteria used for selection were not ascertained.

\section{TREATMENT OF PATIENTS}

Male and female patients with lesions suggestive of herpes were treated before the results of cultures or serological tests for syphilis were known in $90 \%$ and $91 \%$ of clinics, respectively (Table 7$)$. In $12(7 \%)$ clinics consultants reported that they would treat selected male patients and in nine $(5 \%)$ that they would treat selected females immediately, if, for example, they were certain clinically that the disease was herpes or if the patient was in severe pain. In a few clinics patients were treated only after the results of cultures and/or serological tests for syphilis had been obtained.

The treatments varied between clinics. Table 8 shows primary and secondary courses of treatment for both men and women. Primary treatment is defined as that which would be given routinely at the time the diagnosis of herpes was made in cases where the attack was not unusually severe; secondary
Table 7 Clinics treating before results of cultures or serological tests for syphilis

\begin{tabular}{lrrrrr}
\hline & \multicolumn{2}{c}{ Men } & & \multicolumn{2}{c}{ Women } \\
\cline { 2 - 3 } \cline { 6 - 7 } Treatment before results & No. & $\%$ & & No. & $\%$ \\
\hline Patients & 154 & $90 \cdot 1$ & & 157 & $90 \cdot 8$ \\
$\quad$ All & 12 & $7 \cdot 0$ & & 9 & $5 \cdot 2$ \\
Selected & 5 & $2 \cdot 9$ & & 7 & $4 \cdot 0$ \\
None & 171 & $100 \cdot 0$ & & 173 & $100 \cdot 0$ \\
\hline
\end{tabular}

treatment is that which would be used in the first instance only if the attack of herpes was severe, or would be used at a later stage if the lesions had become infected. In almost half the clinics saline washes were initially recommended. Idoxuridine, in strengths ranging from $0.5 \%$ to $40 \%$, was prescribed as the primary treatment for men and women in $22 \%$ and $23 \%$ of clinics, respectively.In an additional $12 \%$ and $14 \%$ of clinics, consultants reported that they would prescribe idoxuridine as a secondary form of treatment. Oral antibiotics were given to all patients in the first instance in approximately one-quarter of clinics, and in almost the same number again, antibiotics would be given if the lesions became infected.

Some form of topical preparation other than idoxuridine was prescribed in approximately $40 \%$ of clinics, usually as a primary course of treatment. These included antibiotic and corticosteroid creams, various spirits, gentian violet, potassium permanganate, and dusting powder. Interferon was used in two clinics, photodynamic inactivation in one, and in three clinics amantadine hydrochloride was prescribed for both men and women.

Table 8 Treatments prescribed for herpes genitalis

\begin{tabular}{|c|c|c|c|c|c|c|c|c|}
\hline \multirow[b]{2}{*}{ Treatment } & \multicolumn{4}{|c|}{ Primary } & \multicolumn{4}{|c|}{ Secondary } \\
\hline & Men & $(N=171)$ & Women & $(N=173)$ & Men & $(N=171)$ & Women & $(N=173)$ \\
\hline & No. & $\%$ & No. & $\%$ & No. & $\%$ & No. & $\%$ \\
\hline None & 1 & 0.6 & 6 & $3 \cdot 5$ & 0 & 0.0 & 5 & 2.9 \\
\hline Saline washes & 82 & $48 \cdot 0$ & 82 & $47 \cdot 4$ & 0 & 0.0 & 0 & 0.0 \\
\hline Idoxuridine & 38 & $22 \cdot 2$ & 39 & $22 \cdot 5$ & 21 & $12 \cdot 3$ & 24 & 13.9 \\
\hline Oral antibiotics & 42 & $24 \cdot 6$ & 46 & $26 \cdot 6$ & 37 & $21 \cdot 6$ & 41 & $23 \cdot 7$ \\
\hline Analgesics & 7 & $4 \cdot 1$ & 7 & $4 \cdot 0$ & 1 & 0.6 & 1 & 0.6 \\
\hline Topical preparations & 65 & $38 \cdot 0$ & 64 & $37 \cdot 0$ & 4 & $2 \cdot 3$ & 5 & 2.9 \\
\hline Antibiotic & 9 & & 8 & & 0 & & 0 & \\
\hline Corticosteroid & 4 & & 3 & & 3 & & 3 & \\
\hline Antibiotic with corticosteroid & 0 & & 2 & & $\mathbf{0}$ & & 0 & \\
\hline Spirits (ether, methylated, surgical) & 8 & & 6 & & 0 & & 0 & \\
\hline Gentian violet/copper sulphate/potassium perman- & & & & & & & & \\
\hline ganate & 10 & & 13 & & 0 & & 0 & \\
\hline Analgesic creams & 3 & & 4 & & 1 & & 2 & \\
\hline Dusting powder & 14 & & 15 & & 0 & & 0 & \\
\hline Other & 17 & & 13 & & 0 & & $\mathbf{0}$ & \\
\hline Interferon & 2 & $1 \cdot 2$ & 2 & $1 \cdot 2$ & 0 & 0.0 & 0 & 0.0 \\
\hline Amantadine hydrochlor (Symmetrel) & 3 & $1 \cdot 8$ & 3 & $1 \cdot 7$ & 0 & 0.0 & 0 & 0.0 \\
\hline Photodynamic inactivation & 0 & 0.0 & 1 & 0.6 & 1 & 0.6 & 1 & 0.6 \\
\hline
\end{tabular}


FOLLOW-UP TESTS

\section{Serological tests}

Table 9 shows that in a large proportion of clinics serological tests for syphilis were repeated at least once after the disappearance of the lesions. However, the last test was carried out less than three months after the patient's initial exposure in 38 $(25 \%)$ of the 154 clinics repeating tests. There was no difference between the clinics that used cultures routinely, in selected cases or not at all, with regard to whether or not serological tests were repeated, the number of repeat tests, or the interval between exposure and final test.

Table 9 Number of occasions on which serological tests for syphilis performed after disappearance of ulceration

\begin{tabular}{lrrrrr}
\hline & \multicolumn{2}{c}{ Men } & & \multicolumn{2}{l}{ Women } \\
\cline { 2 - 3 } \cline { 5 - 6 } No. of occasions & No. & $\%$ & & No. & $\%$ \\
\hline None & 17 & $9 \cdot 9$ & & 19 & $11 \cdot 0$ \\
One & 78 & $45 \cdot 6$ & & 76 & $43 \cdot 9$ \\
Two & 46 & 26.9 & & 46 & $26 \cdot 6$ \\
Three & 21 & $12 \cdot 3$ & & 22 & $12 \cdot 7$ \\
More than three & 7 & $4 \cdot 1$ & & 8 & $4 \cdot 6$ \\
Not known & 2 & $1 \cdot 2$ & & 2 & $1 \cdot 2$ \\
& 171 & $100 \cdot 0$ & & 173 & $100 \cdot 0$ \\
\hline
\end{tabular}

\section{Cervical cytology}

Women with herpes genitalis were advised to have regular cytological examination, usually at yearly intervals, in $104(60 \%)$ of the 173 clinics.

QUARTERLY RETURNS FOR HERPES GENITALIS In all clinics where virus cultures were used, it was reported that cases with a positive virus culture would be included in the quarterly returns for herpes genitalis to the Department of Health and Social Security (DHSS). In 77 of the 171 clinics for men, all or selected patients were treated for herpes genitalis on clinical evidence as virus cultures were not used. The consultants working in $75(97 \%)$ of these clinics reported that they would include such cases in the numbers reported to the DHSS. Similarly, in $75(99 \%)$ of the 76 clinics in which all or some female patients were treated without pathological confirmation of the diagnosis, it was stated that these cases would be included in the quarterly returns for herpes genitalis.

\section{Discussion}

\section{DIAGNOSTIC TESTS}

In a large proportion ( $94 \%$ ) of clinics darkground examinations to exclude syphilis were performed in some or all patients presenting with genital ulceration. However, such examinations should be per- formed on at least three separate occasions to ensure a good chance of identifying Treponema pallidum if it is present (Catterall, 1974; Schofield, 1975). Darkground examinations were performed as often as this in fewer than $40 \%$ of clinics, while in $30 \%$ only one examination was performed. The same principle applies to serological tests for syphilis. These should be repeated three months after the patient's initial exposure. This survey has shown that although in approximately $90 \%$ of clinics serological tests were repeated after the disappearance of the ulceration in both men and women, in onequarter of these the last test was performed less than three months after the patient's initial exposure to risk.

\section{TREATMENT}

There is no universally accepted way of treating herpes genitalis, and the diversity of treatments reflects the inadequacy of current treatment. Virtually all the topical preparations recommended or prescribed-such as saline washes, spirits, paints, and dusting powders - can do little more than give a limited amount of symptomatic relief.

Idoxuridine (IDU) was used as a primary or secondary form of treatment in more than one-third of clinics. While there have been many trials to determine the potential of IDU in shortening the duration of attacks of herpes or preventing recurrences, the reports have been contradictory. Hutfield (1964) found that $0.5 \%$ IDU in ointment shortened the duration of genital herpetic lesions after the beginning of treatment by 2.8 days, compared with an inert preparation. Five per cent IDU in dimethulsylphoxide (DMSO) was shown by MacCallum and Juel-Jensen (1966) to shorten the duration of attacks of oral herpes by $6 \cdot 3$ days, but DMSO alone also resulted in a decrease of $4 \cdot 1$ days. Schofield (1964) reported that of 54 patients treated with $0.5 \%$ IDU in liquid paraffin and white soft paraffin on both oral and genital lesions, only three reported recurrences, but his low follow-up rate must cast doubt upon this finding. Four weeks after their initial visit, over $50 \%$ of the original group had been lost to follow-up, and by three months this proportion had reached $88 \%$.

In contrast, $\mathrm{Ng}$ et al. (1970) reported that they found IDU to have no beneficial effect on the duration of the infection or on the prevention of recurrent disease. In a study comparing photodynamic inactivation, $0.5 \%$ IDU ointment, and normal saline there was no difference between IDU and saline with respect to the relief of pain, the healing time, or the time taken for the virus to disappear as measured by cultures (Taylor and Doherty, 1975). A recent double-blind controlled 
trial comparing $40 \%$ IDU in DMSO with DMSO alone also showed no evidence that the addition of IDU improved the results of treatment in any way (Morgan, 1977, personal communication).

Even if IDU were proved to be beneficial, its side effects - such as contact dermatitis-would militate against its widespread use. Furthermore, Green and Staal (1976) warned against the indiscriminate use of topical IDU in strengths of $5 \%$ or greater, because of its mutagenic potential. In cells pretreated with IDU, they and other workers have found enhanced susceptibility of resistant cell types to infection by cytomegalovirus and adenoviruses, enhanced replication of many other RNA and DNA viruses, and induction of infectious virus production in cells with integrated viral genomes, including viruses associated with human and animal neoplasia.

We have reported that photodynamic inactivation has not been widely adopted as a method of treatment for herpes genitalis in this country. An early report of its effects was encouraging (Felber et al., 1973) but two subsequent studies in which neutral red dye was compared with a non-photoactive dye, phenolsulfonphthalein, failed to show any difference in the duration of patients' discomfort, the healing time of the lesions, the time taken to eliminate the infective virus, or the length of time between recurrences (Myers et al., 1975; Roome et al., 1975). Cusumano and Monif (1975) also suggested that the inactivation of the virus is only partial. While the damage is sufficient to prevent it from producing lesions, the apparently inactivated virus particles can still be capable of transforming a cell, and thus giving rise to local malignancies, but only after a delay of many years.

It is understandable that many consultants, although aware that little can be done to shorten the duration of the lesions, hope that some form of therapy will be of some psychological benefit to the patient. However, in view of the equivocal evidence on the efficacy of IDU and photodynamic inactivation, their potential side effects and expense, it is suggested that their use is not justified.

CARCINOMA OF THE CERVIX

The possibility of an association between herpes genitalis and carcinoma of the cervix has now been the subject of debate for more than a decade. Evidence supporting the existence of a relationship has been mainly provided by a series of seroepidemiological studies comparing the prevalence of antibodies to herpes virus Type 2 among women with dysplasia, carcinoma in situ, and invasive carcinoma with that found in control groups (Rawls et al., 1968, 1969; Nahmias et al., 1970;

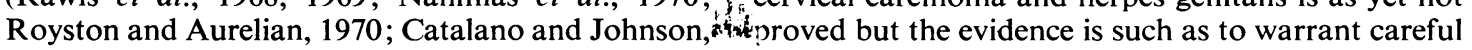

1971; Skinner et al., 1971). These studies consistently show that positive antibodies are more common among women with dysplasia, carcinoma in situ, and invasive carcinoma than among their respective controls, and furthermore that they are less common among women with dysplasia than among those with carcinoma in situ, and most prevalent among women with invasive carcinoma. However, the control groups in these studies were not matched for age at first sexual intercourse or number of sexual partners. Since both of these factors have been shown to be related to the prevalence of carcinoma of the cervix (Lombard and Potter, 1950; Wynder et al., 1954), it is possible that sexual promiscuity is a covariable affecting both the risk of developing cervical cancer and the risk of exposure to herpes genitalis.

More recently, Nahmias et al. (1973) reported preliminary results of a prospective study undertaken to evaluate the risk of cervical anaplasia developing after the detection of genital herpetic infection. They found that the rate of cervical dysplasia was twice as great, and that of in situ carcinoma eight times higher in the herpes group than in a control group in whom Type 2 antibodies could not be detected.

Despite these reports, it still cannot be said that herpes genitalis causes cervical cancer. However, the virus is under sufficient suspicion for it to be strongly recommended that a viral culture service should be available to all clinics and that cervical virus cultures should be performed routinely. Furthermore, all women with herpes genitalis should be advised to have cytological examination at regular intervals. This study has shown that cervical virus cultures were performed in only one-third of clinics with a virus culture service, and that in $40 \%$ of clinics women with herpes genitalis were not recommended to have cytology.

\section{Conclusions}

It is important that syphilis be excluded in all patients with genital ulceration. It is to be hoped, therefore, that consultants will increase both the number of patients on whom darkground examinations are performed and the number of occasions on which these examinations are carried out, and that final serological tests for syphilis be repeated at least three months after initial exposure to risk. In view of the relative ineffectiveness of IDU and photodynamic inactivation it is suggested that palliative therapy is the most appropriate and least expensive treatment. The association between cervical carcinoma and herpes genitalis is as yet not 
cytological follow-up of all women with genital herpes.

This study was supported as part of a project grant from the Medical Research Council. We should like to thank Dr B. H. O'Connor for carrying out a substantial number of interviews. We are most grateful to Dr R. D. Catterall and Professor D. L. Miller for their encouragement and support and to Dr C. S. Nicol and Dr R. S. Morton for their advice. We are particularly grateful to $\mathrm{Dr}$ R. R. Willcox for his generous advice on the design of the study.

\section{References}

Adler, M. W., Belsey, E. M. O'Connor, B. H., Catterall, R. D., and Miller, D. L. (1978). Facilities and diagnostic criteria in sexually transmitted disease clinics in England and Wales. British Journal of Venereal Diseases, 54, 2-9.

Catalano, L. W., and Johnson, L. D. (1971). Herpesvirus antibody and carcinoma in situ of the cervix. Journal of the American Medical Association, 217, 447-450.

Catterall, R. D. (1974). A Short Textbook of Venereology: The Sexually Transmitted Diseases, p. 177. English Universities Press: London.

Cusumano, C. L., and Monif, G. R. G. (1975). A word of caution concerning photodynamic inactivation therapy for Herpesvirus hominis infections. Obstetrics and Gynecology, 45, 335-336.

Felber, T. D., Smith, E. B., Knox, J. M., Wallis, C., and Melnick, J. L. (1973). Photodynamic inactivation of herpes simplex. Journal of the American Medical Association, 223, 289-292.

Green, J., and Staal, S. (1976). Questionable dermatologic use of iododeoxyuridine. New England Journal of Medicine, 295, 111-112.

Hutfield, D. C. (1964). Effects of 5-iodo-2'-deoxyuridine and phenylmercuric dinaphthylmethane disulphonate on herpes genitalis. British Journal of Venereal Diseases, 40, 210-212.

Lombard, H. L., and Potter, E. A. (1950). Epidemiological aspects of cancer of the cervix. Cancer, 3, 960-968.
MacCallum, F. O., and Juel-Jensen, B. E. (1966). Herpes simplex virus skin infection in man treated with idoxuridine in dimethy sulphoxide. Results of double-blind controlled trial. British Medical Journal, 2, 805-807.

Myers, M. G., Oxman, M. N., Clark, J. E., and Arndt, K. A. (1975). Failure of neutral-red photodynamic inactivation in recurren herpes simplex virus infections. New England Journal of Medicine, 293, 945-949.

Nahmias, A. J., Josey, W. E., Naib, Z. M., Luce, C. F., and Guest, B. A. (1970). Antibodies to Herpesvirus hominis types 1 and 2 in humans. II. Women with cervical cancer. American Journal of Epidemiology, 91, 547-552.

Nahmias, A. J., Naib, Z. M., Josey, W. E., Franklin, E., and Jenkins, R. (1973). Prospective studies of the association of genital herpes simplex infection and cervical anaplasia. Cancer Research, 33. 1491-1497.

$\mathrm{Ng}$, A. B. P., Reagan, J. W., and Yen, S. S. C. (1970). Herpes genitalis. Obstetrics and Gynecology, 36, 645-651.

Rawls, W. E., Tompkins, W. A. F., Figueroa, M. E., and Melnick, J. L. (1968). Herpesvirus type 2: Association with carcinoma of the cervix. Science, 161, 1255-1256.

Rawls, W. E., Tompkins, W. A. F., and Melnick, J. L. (1969). The association of herpesvirus type 2 and carcinoma of the uterine cervix. American Journal of Epidemiology, 89, 547-554.

Roome, A. P. C. H., Tinkler, A. E., Hilton, A. L., Montefiore, D. G., and Waller, D. (1975). Neutral red with photoinactivation in the treatment of herpes genitalis. British Journal of Venereal Diseases, 51, 130-133.

Royston, I., and Aurelian, L. (1970). The association of genital herpesvirus with cervical atypia and carcinoma in situ. American Journal of Epidemiology, 91, 531-538.

Schofield, C. B. S. (1964). The treatment of herpes progenitalis with 5-iodo-2'-deoxyuridine. British Journal of Dermatology, 76, 465-470.

Schofield, C. B. S. (1975). In Recent Advances in Sexually Transmitted Diseases, p. 76. Edited by R. S. Morton and J. R. W. Harris. Churchill Livingstone: London.

Skinner, G. R. B., Thouless, M. E., and Jordan, J. A. (1971). Antibodies to type 1 and type 2 herpes virus in women with abnormal cervical cytology. Journal of Obstetrics and Gynaecology of the British Commonwealth, 78, 1031-1038.

Taylor, P. K., and Doherty, N. R. (1975). Comparison of the treatment of herpes genitalis in men with proflavine photoinactivation, idoxuridine ointment, and normal saline. British Journal of Venereal Diseases, 51, 125-129.

Wynder, E. L., Cornfield, J., Shroff, P. D., and Doraiswami, K. R. (1954). A study of environmental factors in carcinoma of the cervix. American Journal of Obstetrics and Gynecology, 68, 10161052. 